\title{
Implementasi Metode On-Page Search Engine Optimization untuk Meningkatkan Peringkat Website sebagai Hasil Pencarian Google
}

\author{
http://dx.doi.org/10.28932/jutisi.v7i1.3428 \\ Riwayat Artikel \\ Received: 21 Februari 2021 | Final Revision: 22 Maret 2021 | Accepted: 31 Maret 2021
}

\author{
Antonius ${ }^{\# 1}$, Bernard Renaldy Suteja ${ }^{{ }^{* 2}}$ \\ \#*Magister Ilmu Komputer, Universitas Kristen Maranatha \\ Jl. Prof.Drg. Surya Sumantri, MPH 65. Bandung \\ 11879001 @maranatha.ac.id \\ 2bernard.rseit.maranatha.edu
}

\begin{abstract}
Current development of the internet world has been growing rapidly, especially in the field of website. People use search engines to find the news or information they needed on a website. One of the many indications of the success of a website is traffic. Traffic could be received from various factors, one of which is website rank in Search Engine Result Page (SERP). To improve the SERP, SEO methods are required. By implementing SEO methods, the efforts to get the best position in Google SERP will be easier. Website will be useless with no visitors or difficult to find. This is one of the problems experienced by XYZ University's website, where visitors of university's website are still few and quite difficult to find on the SERP. This research will implement SEO to XYZ University's website, and then analyzed by using a tester tools, for example SEOptimer, Pingdom Tools, and SEO Site Checkup. After the website has been optimized, tested with the same tester tools. From the research results can be seen whether SEO can affect SERP.
\end{abstract}

Keywords—image, implementation; search engine; SEO; SERP

\section{Pendahuluan}

Pada perkembangan internet saat ini, orang-orang menggunakan mesin pencari seperti Google, untuk mencari informasi di sebuah website, baik itu berupa artikel teks, gambar, video, buku, dan lain-lain. Untuk menjawab kebutuhan tersebut, banyak organisasi maupun individual membuat website dengan tampilan, responsivitas, kecepatan, dan keamanan yang baik. Namun, sangat disayangkan tidak sedikit yang melupakan hal yang sangat penting, yaitu bagaimana website tersebut dapat dengan mudah untuk ditemukan oleh pengunjung pada mesin pencari [1].
Website Universitas XYZ merupakan portal digital utama Universitas XYZ dan berperan sebagai media informasi serta identitas bagi Universitas XYZ. Namun website Universitas XYZ sepi pengunjung dan cukup sulit untuk ditemukan pada hasil pencarian mesin pencari (SERP). Padahal website yang menempati posisi teratas pada SERP memiliki peluang lebih besar untuk mendapatkan pengunjung [2]. Untuk memecahkan permasalahan tersebut, website Universitas XYZ harus dengan mudah ditemukan di mesin pencari oleh pengunjung. Dan untuk memudahkan pengunjung untuk menemukan website tersebut dari mesin pencari, dibutuhkan peringkat SERP (Search Engine Result Page) yang baik, minimal website berada di halaman pertama pada SERP.

Diperlukan sebuah metode untuk memperbaiki struktur website dan meningkatkan peringkat website pada SERP dan optimasi gambar yang dikenal sebagai metode SEO [3]. Dengan optimasi SEO, tentunya akan mempermudah pengunjung website universitas untuk menemukan informasi yang mereka butuhkan.

Berdasarkan latar belakang tersebut, maka dapat dirumuskan rumusan masalah yang akan dibahas, diteliti, dan dipecahkan, yaitu:

1. Apakah implementasi metode SEO pada website Universitas XYZ efektif dalam meningkatkan peringkat website di hasil pencarian?

2. Bagaimana cara menganalisis hasil implementasi metode on-page SEO tersebut?

Melihat permasalahan di atas maka dilakukan penelitian mengenai Implementasi Metode On-Page SEO Untuk Meningkatkan Peringkat Website Universitas XYZ di Hasil Pencarian Google. 
Tujuan dari penelitian ini adalah untuk memecahkan permasalahan website Universitas XYZ, khususnya melalui implementasi metode on-page SEO untuk meningkatkan peringkat website pada hasil pencarian Google, sehingga website universitas dapat lebih mudah untuk ditemukan oleh pengunjung website. Adapun tujuan lain dari penelitian ini adalah untuk menganalisis hasil implementasi metode onpage SEO agar medapat kesimpulan atau evaluasi dari implementasi SEO yang telah dilakukan.

Penelitian ini dilakukan pada website utama Universitas XYZ, salah satu perguruan tinggi terbaik di kota Bandung, yang meliputi implementasi metode on-page SEO. Dalam penelitian ini, dianalisis pengaruh metode SEO pada peringkat SERP di mesin pencari Google yang dilakukan selama 9 bulan terhitung dari bulan Januari 2020 sampai dengan bulan September 2020.

\section{KAJIAN TEORI}

\section{A. Mesin Pencari}

Mesin pencari merupakan program komputer yang digunakan untuk membantu pencarian informasi di internet. Mesin pencari biasanya diakses melalui halaman di situs web yang memungkinkan pengguna untuk mencari konten miliaran website di web dengan memasukkan serangkaian kata kunci ke dalam kotak teks pencarian [1]. Kata kunci yang dikirimkan oleh pengguna kemudian akan dicocokkan dengan halaman yang di-cache atau diindeks dalam database mesin pencari dan daftar referensi yang cocok dengan kata kunci atau kriteria kata kunci akan dikembalikan [4].

\section{B. Mesin Pencari Google}

Google adalah mesin pencari paling populer dan yang tercanggih pada saat ini. Mesin pencari Google mampu menampilkan hasil pencarian yang lebih baik, lebih cepat, dan lebih cerdas dibandingkan mesin pencari lainnya. Google akan menampilkan hasil pencarian yang relevan sesuai dengan kata kunci yang dicari oleh pengguna [5]. Pada SERP, mesin pencari Google akan menampilkan website yang relevan, iklan Google Ads, Google bisnis, video Youtube dan penelusuran terkait. Hasil pencarian yang ditampilkan mesin pencari Google sudah melalui proses terlebih dahulu, sehingga yang ditampilkan pada halaman pertama adalah yang terbaik serta memenuhi syarat dari Google.

\section{Crawler Based Search Engine}

Mesin pencari berbasis crawler berisi 3 bagian, yaitu: crawler (bot atau robot) yang menjelajahi website dan membuat daftar halaman website, kemudian indeks yang merupakan kumpulan besar salinan halaman website, dan software mesin pencari yang memberikan peringkat hasil. Karena crawler pada mesin pencari ini mencari web terusmenerus, halaman website yang terdapat dalam indeks akan selalu diperbarui [6]. Contoh mesin pencari yang berbasis crawler: Google, WebCrawler, Inktomi, dan Fast Search.

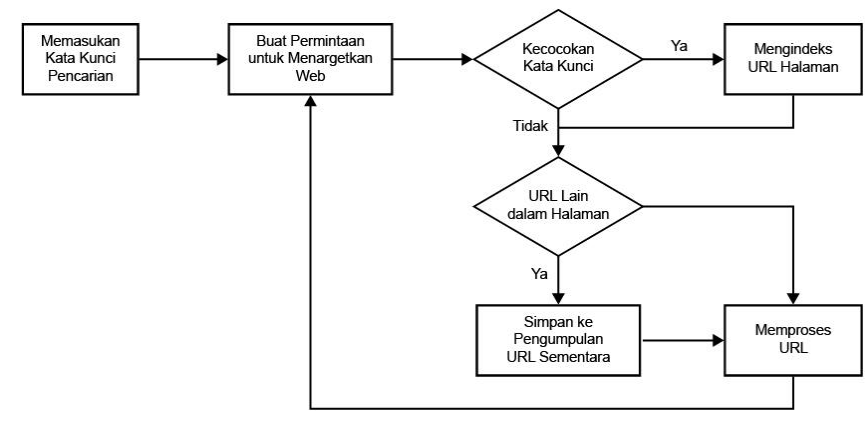

Gambar 1. Proses Web Crawler pada Mesin Pencari

\section{Search Engine Optimization (SEO)}

SEO merupakan sebuah proses untuk meningkatkan struktur website dan mempromosikannya agar muncul di mesin pencari, meningkatkan peringkatnya dan jumlah pengunjung. Ada banyak cara untuk menerapkan SEO untuk website, mulai dari kata kunci di halaman web hingga cara website lain terhubung ke website tersebut [4]. SEO pertama kali digunakan oleh sebuah pesan SPAM yang di posting di Usenet pada tanggal 26 Juli 1997. SEO dapat didefinisikan sebagai suatu rangkaian proses yang dilakukan secara sistematis untuk meningkatkan volume dan kualitas traffic kunjungan melalui website tertentu dengan memanfaatkan mekanisme kerja atau algoritma mesin pencari tersebut [7]. Daffy Shaci, salah satu master SEO di Indonesia, mengatakan bahwa melalui SEO website dapat menempati posisi atau halaman pertama pada mesin pencari. Tujuan dari SEO ialah untuk menempatkan sebuah website pada posisi teratas, setidaknya pada halaman pertama dari SERP berdasarkan kata kunci yang diinput oleh pengguna.

\section{E. On-page SEO}

Optimasi on-page SEO merupakan teknik yang memungkinkan mesin pencari untuk memahami konten dalam sebuah halaman web [1]. On-page SEO mengoptimalkan struktur halaman untuk mesin pencari dan pengguna, seperti: meta title (title tag), nama domain, deskripsi halaman web (meta description), ALT tag pada gambar, dan kecepatan dalam memuat website.

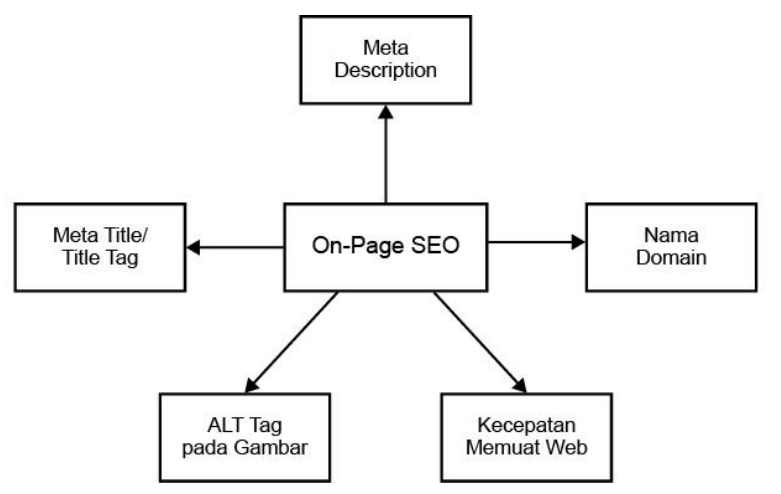

Gambar 2. Jenis-Jenis Optimasi pada On-Page SEO 


\section{F. Parameter SEO}

Metode SEO bisa dikatakan berhasil jika memenuhi beberapa parameter di bawah ini:

1. Website berada di peringkat teratas di SERP. Sebanyak $62 \%$ pengguna internet hanya tertarik pada 10 hingga 20 dari daftar website pertama pada halaman SERP. Dan untuk $38 \%$ sisanya melihat website yang ada pada halaman berikutnya [8].

2. Bertambahnya traffic/pengunjung yang mengunjungi website, karena dengan munculnya website pada peringkat teratas di SERP maka peluang untuk mendapatkan pengunjung menjadi lebih besar.

3. Pagerank, karena Pagerank merupakan salah satu produk mesin pencari Google dalam mengelompokkan website sesuai dengan algoritma Google.

\section{TINJAUAN PUSTAKA}

Implementasi SEO dapat menempatkan website pada posisi teratas di SERP berdasarkan kata kunci tertentu. Website yang menempati posisi teratas di SERP memiliki peluang lebih besar untuk ditemukan oleh pengunjung. Selain itu melalui penerapan SEO, kunjungan traffic akan meningkat pada SERP mesin pencari.

Menurut Aziz Barbar dan Anis Ismail dalam penelitiannya yang berjudul Search Engine Optimization (SEO) for Websites, metode SEO dapat menyelesaikan permasalahan jumlah visitor pada website. Teknik yang digunakan adalah dengan meningkatkan beberapa struktur website sehingga search-engine-friendly, sehingga web crawler dapat membaca, menganalisa, dan mengindeks konten website dengan lebih mudah [1]. Pendekatan yang dilakukan oleh Aziz Barbar dan Anis Ismail pada penelitian ini efektif untuk meningkatkan peringkat website dengan menerapkan SEO, yaitu melalui: (1) teknik on-page SEO yang membantu web crawler untuk mengerti konten pada halaman website, (2) teknik off-page SEO yang menganalisa aspek di luar konten halaman, dan (3) media sosial yang menambah peringkat website melalui share atau like [1].

Menurut Wang Bin dan Gao Bingyun dalam penelitian yang berjudul A Study on Tactics for College Website at Search Engine Optimization, implementasi SEO terhadap website, yaitu: kata kunci, halaman website, link eksternal dan aspek lainnya pada website universitas School of Continuing Education Ocean University of China dapat meningkatkan peringkat website tersebut. Dijelaskan bahwa dengan menerapkan metode SEO, pengguna dapat dengan cepat dan mudah untuk mengakses informasi yang mereka butuhkan. Peringkat website perlu ditingkatkan pada SERP sehingga visitor dapat meningkat. Peningkatan terhadap aspek-aspek melalui metode SEO ini merupakan strategi yang tepat untuk membangun brand yang baik bagi universitas [3].

Dalam penelitian Search Engine Optimization to Detect User's Intent, Salma Gaou, Aissam Bekkari, Marouane El Mabrouk, dan Abdelhamid Zouhair menyimpulkan bahwa dengan memahami maksud/tujuan pengguna pada pencarian, jenis konten dapat ditentukan dengan lebih terarah sehingga meningkatkan visibilitas dan kualitas dari konten pada sebuah website. Mereka melakukan pendekatan baru melalui metode SEO dengan menghitung efisiensi indeks kata kunci (KEI), sehingga dapat meningkatkan peringkat website. Dengan menghitung algoritma pencarian yang diterapkan pada penelitian ini, akan didapatkan data maksud/tujuan pengguna sehingga dapat dianalisis metode SEO terhadap konten website dengan tepat [9].

Menurut Dr. Birgit Weischedel dan Dr. Eelko K.R.E. Huizingh (2006) dalam penelitian yang berjudul Website Optimization with Web Metrics: A Case Study, penggunaan web metrics khususnya menggunakan data clickstream dapat mengoptimasi sebuah website. Melalui web metrics, dapat diukur bagaimana pengguna menggunakan sebuah website. Pada penelitian melalui data clickstream tersebut didapatkan hasil bahwa dari 200.000 visitor yang membuka beranda sebuah website, hanya $10 \%$ saja yang membaca halaman lainnya. Web metrics kemudian digunakan untuk mengevaluasi keberhasilan dari implementasi yang dilakukan. Selanjutnya web metrics ini dapat digunakan untuk penggunaan survei untuk mengetahui impresi dan apa yang dipikirkan oleh pengguna terhadap sebuah website. Penelitian yang dilakukan oleh Dr. Birgit Weischedel dan Dr. Eelko K.R.E. Huizingh membahas secara rinci mengenai penerapan web metrics untuk mengoptimasi sebuah website [10].

Mo Yunfeng dalam penelitiannya yang berjudul A Study on Tactics for Corporate Website Development Aiming at Search Engine Optimization, mempelajari taktik untuk pengembangan website korporat melalui SEO. Taktik yang dilakukan adalah optimasi nama domain/host, konten website, kata kunci, dan tautan. Taktik yang dilakukan didukung oleh data yang didapatkan melalui penghitungan algoritma PageRank, algoritma HillTop, dan gabungan dari keduanya [11].

Menurut Chaitanya Vyas dalam papernya yang berjudul Evaluating State Tourism Websites Using Search Engine Optimization Tools, optimasi website menggunakan metode SEO pada sebuah website pariwisata negara dapat meningkatkan website pada peringkat pertama pada mesin pencari. Karena website memiliki peran yang sangat penting untuk memasarkan pariwisata negara secara digital, website harus muncul pada peringkat teratas pada mesin pencari saat turis mencari informasi mengenai sebuah negara dan berencana untuk berwisata [12].

Selanjutnya Li-Hsing Ho dan Jui-Chen Huang dalam penelitiannya yang berjudul The Application of Search Engine Optimization for Internet Marketing: An Example of the Motel Websites, aplikasi SEO sangat membantu pemasaran melalui internet sebuah website motel. Proses yang dilakukan pada penelitian tersebut adalah dengan memodifikasi HTML title, ALT tag, teks judul/teks tabel, mendaftarkan website ke dalam DMOZ open website catalog, mendaftarkan website ke mesin pencari utama, mengeksekusi WEB PING ke mesin pencari utama, 
memanfaatkan nama sub-domain untuk mengaplikasikan SEO, dan menyediakan sitemap ke mesin pencari. Penelitian tersebut menghasilkan bandwidth dan peringkat dari website motel yang meningkat setelah diaplikasikan proses SEO. Modifikasi pada HTML title dan ALT tag merupakan aspek penting untuk menerapkan SEO, penelitian yang dilakukan oleh Li-Hsing Ho sangat mendalam dan menyertakan bagaimana proses pengaplikasian SEO dari awal hingga akhir pada website motel yang ditelitinya [13].

\section{MEtodologi PENELITIAN}

Metode penelitian yang digunakan dalam penelitian ini adalah metode penelitian kuantitatif deskriptif, di mana data yang diperoleh didapatkan dari sebuah website yang mendeskripsikan secara sistematik, faktual, dan akurat dengan pendekatan studi kasus (case study), melalui serangkaian pengujian yang dilakukan. Pada penelitian ini akan dilakukan pengujian pre-test dan post-test, kemudian paired sample t-test untuk mengetahui peningkatan peringkat website Universitas XYZ di hasil pencarian Google sebelum dan sesudah implementasi metode SEO.

\section{A. Langkah Penelitian}

Langkah-langkah yang dilakukan dalam penelitian ini adalah sebagai berikut:

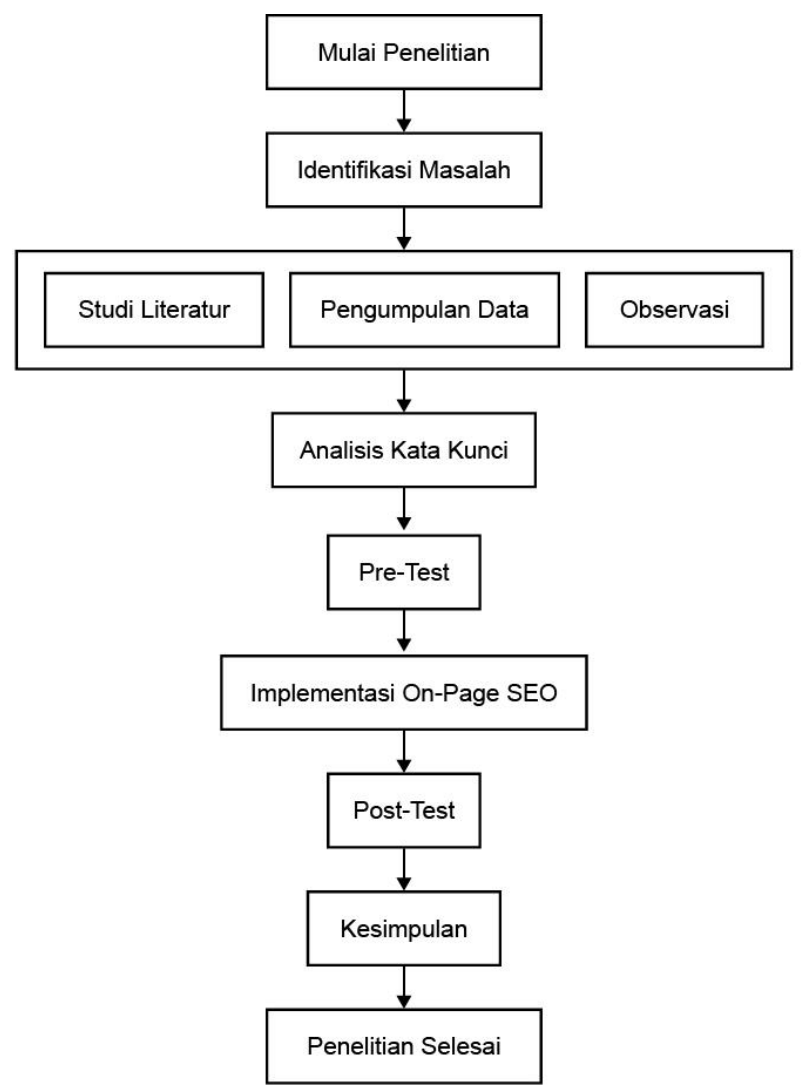

Gambar 3. Diagram Langkah Penelitian

\section{Identifikasi Masalah}

Pada tahap ini dilakukan identifikasi masalah pada website Universitas XYZ. Identifikasi masalah terpusat pada website utama universitas yang sulit untuk ditemukan oleh pengunjung website.

2. Studi Literatur, Pengumpulan Data, dan Observasi Metodologi yang dilakukan adalah studi literatur agar mendapatkan teori dan referensi literatur yang relevan dengan penelitian, dan menmbah wawasan terhadap penelitian yang sedang dikerjakan. Pengumpulan data dilakukan dengan menggunakan beberapa tools SEO dan observasi website di lapangan.

3. Analisis Kata Kunci

Tahap ini dilakukan untuk menentukan kata kunci yang relevan digunakan sesuai dengan kata kunci yang paling sering dicari oleh pengunjung website universitas.

4. Pre-Test

Sebelum implementasi SEO dilakukan pada website, dilakukan pre-test pada website Universitas XYZ. Hal ini dilakukan agar dapat menjadi pembanding sebelum dan sesudah dilakukan metode SEO pada website Universitas XYZ.

5. Implementasi On-Page SEO

Website Universitas XYZ dioptimasi dengan menggunakan metode on-page SEO. Optimasi yang dilakukan adalah optimasi meta description, ALT tag pada gambar, internal link, dan site speed.

6. Post-Test

Setelah website dioptimasi selama beberapa bulan, perlu dilakukan pengetesan ulang peringkat SERP serta pengujian website. Tes ini dilakukan untuk mengetahui perbedaan posisi peringkat pencarian serta kondisi website sebelum dan sesudah dilakukan optimasi SEO pada website Universitas XYZ.

7. Kesimpulan

Tahap terakhir ini adalah tahap yang merangkum hasil akhir dari penelitian yang telah dilakukan.

\section{B. Hipotesis}

Berdasarkan rumusan masalah, kajian teori, tinjauan pustaka dan analisis awal maka didapatkan hipotesis komparatif sebagai berikut:

1. $\mathrm{H}_{0}$, Tidak ada perbedaan peringkat website Universitas XYZ di hasil pencari Google antara sebelum dan sesudah implementasi metode on-page SEO $(\mu 1 \leq \mu 2)$.

2. $\mathrm{H}_{1}$, Implementasi metode on-page SEO pada website Universitas XYZ mampu meningkatkan peringkat website di hasil pencari Google dibandingkan dengan tanpa implementasi SEO $(\mu 1>\mu 2)$.

\section{IMPLEMENTASI \& ANALISIS}

\section{A. Analisis Kata Kunci}

Sebagai acuan analisis peringkat SERP, kata kunci yang relevan dicari menggunakan tools Google Keyword Planner untuk mengetahui kata kunci mana saja yang paling banyak 
dicari oleh pengguna mesin pencari Google yang terkait dengan Universitas XYZ pada tahun 2019. Tabel di bawah ini merupakan hasil rekomendasi kata kunci yang diberikan oleh Google Keyword Planner. Sepuluh kata kunci yang paling banyak dicari diambil sebagai acuan pada analisis peringkat di SERP.

TABEL I

Hasil ReKOMENDASI Kata KUnCI Di GOOGLE Keyword PlanNER

\begin{tabular}{|l|l|l|}
\hline Rekomendasi Kata Kunci & $\begin{array}{l}\text { Rata-Rata } \\
\text { Dicari Tiap } \\
\text { Bulan }\end{array}$ & $\begin{array}{l}\text { Tingkat } \\
\text { Persaingan }\end{array}$ \\
\hline jurusan kuliah & $10 \mathrm{~K}-100 \mathrm{~K}$ & Rendah \\
\hline universitas terbaik di bandung & $10 \mathrm{~K}-100 \mathrm{~K}$ & Rendah \\
\hline masuk kampus & $1-10 \mathrm{~K}$ & Rendah \\
\hline beasiswa kuliah & $1-10 \mathrm{~K}$ & Rendah \\
\hline universitas swasta terbaik & $1-10 \mathrm{~K}$ & Rendah \\
\hline fakultas kedokteran & $1-10 \mathrm{~K}$ & Rendah \\
\hline penerimaan mahasiswa baru & $1-10 \mathrm{~K}$ & Rendah \\
\hline kampus terbaik di bandung & $1-10 \mathrm{~K}$ & Rendah \\
\hline perguruan tinggi swasta & $1-10 \mathrm{~K}$ & Rendah \\
\hline perguruan tinggi swasta terbaik & $1-10 \mathrm{~K}$ & Rendah \\
\hline
\end{tabular}

\section{B. Pre-Test}

Pada tahap ini dilakukan beberapa pengujian terhadap website Universitas XYZ, baik dari kondisi traffic maupun peringkat website dari hasil pencarian Google. Hal ini dilakukan agar didapatkan data sebagai pembanding dari sebelum dan sesudah implementasi metode SEO pada website Universitas XYZ.

Pengujian pertama dilakukan dengan menggunakan Google Analytics. Traffic website Universitas XYZ selama setengah tahun dari Oktober 2019-Maret 2020 adalah sebagai berikut:

TABEL III

DATA TRAFFIC WEBSITE UNIVERSITAS XYZ SEBELUM IMPLEMENTASI SEO

\begin{tabular}{|l|l|c|c|}
\hline Pageviews & \multicolumn{1}{|c|}{$\begin{array}{c}\text { Unique } \\
\text { Pageviews }\end{array}$} & $\begin{array}{c}\text { Bounce } \\
\text { Rate }\end{array}$ & \%Exit \\
\hline 201.884 & 150.361 & $57,10 \%$ & $45,26 \%$ \\
\hline
\end{tabular}

Dari Tabel II dapat diketahui jumlah kualitas pengunjung dengan cara:

- Nilai yang bukan bounce rate $(\%)$

$100 \%-57,10 \%=42,9 \%$

- Jumlah yang membaca dan mem-browser website Universitas XYZ adalah:

(jumlah unique pageviews) x (bukan bounce rate)

$150.361 \times 42,9 \%=64.505$ pengunjung

Jadi, ada sebanyak 64.505 pengunjung yang benar-benar membaca website Universitas XYZ.

Pengujian kedua dilakukan dengan menguji sepuluh kata kunci yang didapatkan dari Google Keyword Planner dengan menggunakan Whatsmyserp untuk mengetahui peringkat website Universitas XYZ untuk setiap kata kunci tersebut di hasil pencarian Google. Dari Gambar 4 diketahui bahwa kata kunci yang terdapat pada website Universitas XYZ belum memiliki peringkat karena website belum dioptimasi. Website Universitas XYZ tidak muncul pada 100 hasil pencarian pertama di mesin pencari Google, sehingga akan sangat sulit untuk ditemukan oleh pengunjung. Dari sepuluh kata kunci, website Universitas XYZ hanya muncul di peringkat 83 untuk kata kunci fakultas kedokteran di mesin pencari Google.

\section{Google SERP \& Rank Checker}

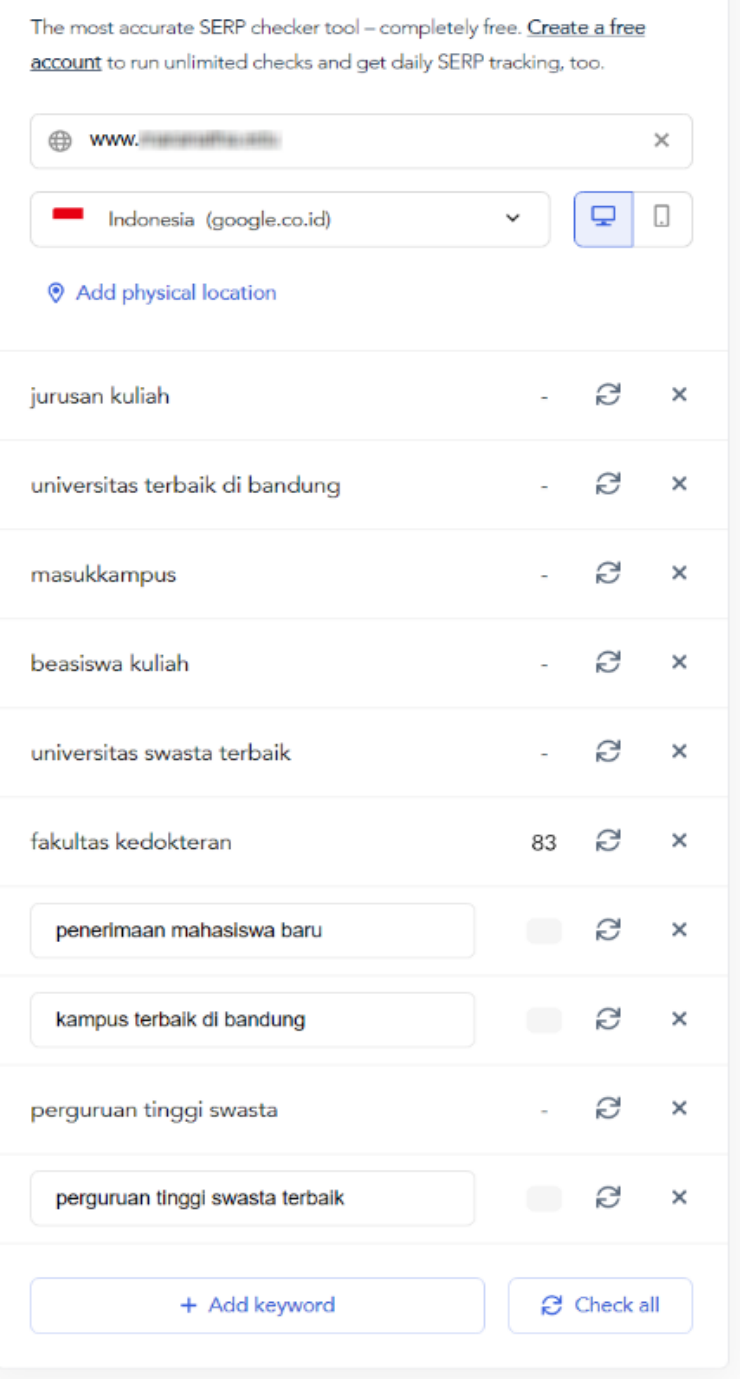

Gambar 4. Peringkat SERP Website Universitas XYZ Berdasarkan Kata Kunci Sebelum Implementasi SEO

Pengujian ketiga adalah menggunakan PageRank untuk mengetahui peringkat website Universitas di hasil pencarian Google. PageRank menunjukkan data pada tabel berikut: 
TABEL IIIII

DATA PERINGKAT WEBSITE UNIVERSITAS XYZ MENGGUNAKAN PAGERANK SEBELUM IMPLEMENTASI SEO

\begin{tabular}{|c|l|l|}
\hline No. & \multicolumn{1}{|c|}{ Indikator } & \multicolumn{1}{c|}{ Total } \\
\hline 1 & Global Rank & 80.665 \\
\hline 2 & Alexa Reach Rank & 77.841 \\
\hline
\end{tabular}

Kemudian pengujian berikutnya dilakukan menggunakan SEO Site Checkup untuk mengetahui penilaian SEO terhadap website tersebut. Dari pengujian yang dilakukan didapatkan hasil seperti pada Gambar 5.

\section{SEO Site Checkup score:}

\section{http://www.}
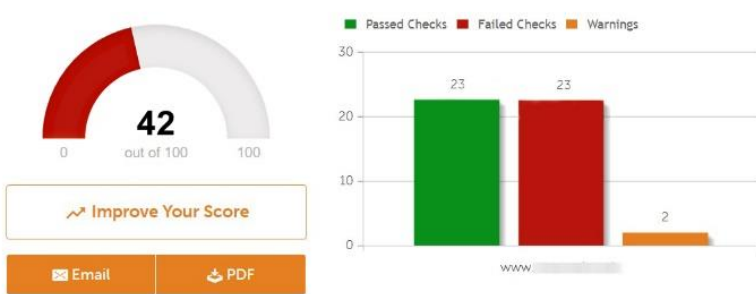

Gambar 5. SEO Site Checkup Score Sebelum Implementasi SEO

Nilai yang diperoleh adalah 42/100, hasil ini cukup rendah dan menunjukkan bahwa website belum dioptimasi. Data dari SEO Site Checkup menunjukkan bahwa website Universitas XYZ memiliki beberapa hal yang belum dioptimasi, seperti daftar masalah umum berikut ini:

TABEL IVV

DAFTAR MASALAH UMUM YANG PERLU DiOPTIMASI

\begin{tabular}{|c|l|c|c|}
\hline \multirow{2}{*}{ No. } & \multicolumn{2}{|c|}{ Masalah Umum } & \multicolumn{2}{c|}{ Status Optimasi } \\
\cline { 3 - 4 } & & Sudah & Belum \\
\hline 1 & Meta title & $\mathrm{V}$ & \\
\hline 2 & Meta description & & $\mathrm{V}$ \\
\hline 3 & Heading tags & & $\mathrm{V}$ \\
\hline 4 & Image ALT tag & & $\mathrm{V}$ \\
\hline 5 & Internal link & & $\mathrm{V}$ \\
\hline 6 & Site speed & & \\
\hline
\end{tabular}

Pengujian berikutnya adalah untuk mengetahui hasil pencarian gambar pada mesin pencari Google terhadap website Universitas XYZ. Hal ini dilakukan untuk mengetahui kondisi gambar pada mesin pencarian sebelum gambar dioptimasi, agar dapat dibandingkan dengan kondisi setelah gambar dioptimasi.

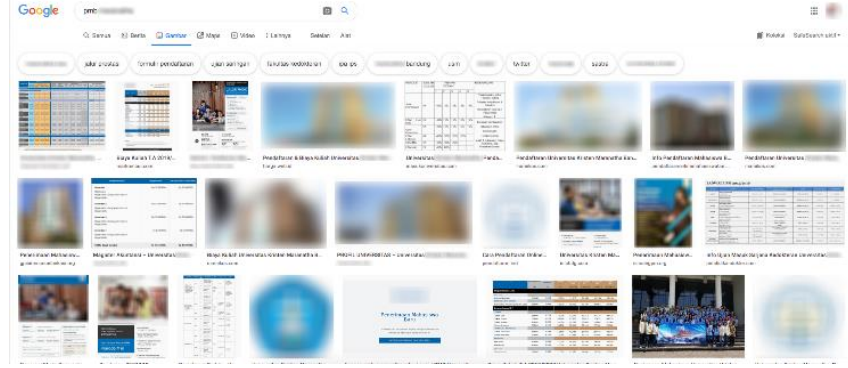

Gambar 6. Hasil SERP dari Kata Kunci PMB XYZ di Mesin Pencari Gambar Google Sebelum Dioptimasi

Dari hasil pengecekan, diketahui bahwa gambar di website Universitas XYZ tidak diindeks oleh mesin pencari, hal ini dikarenakan mesin pencari tidak dapat membaca gambar pada website Universitas XYZ. Hasil pencarian menampilkan gambar terkait secara acak yang tidak sesuai dengan kata kunci yang dicari di mesin pencarian.

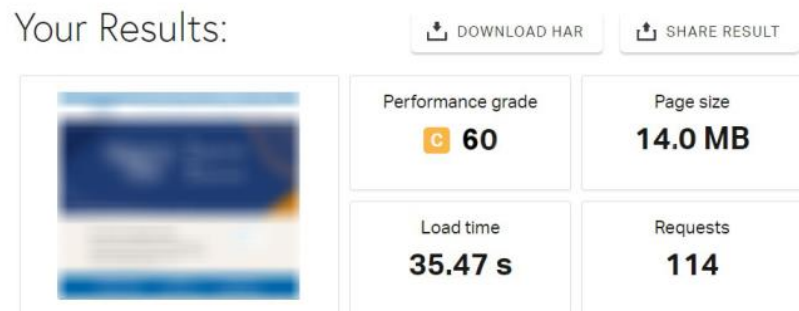

Gambar 7. Hasil Pengujian Site Speed Menggunakan Pingdom Tools Sebelum Implementasi SEO

Pengujian terakhir dilakukan menggunakan Pingdom Tools untuk mendapatkan pengukuran lamanya waktu website Universitas XYZ dimuat. Menurut riset Google, 53 persen pengguna internet Indonesia akan meninggalkan website dengan waktu memuat lebih dari 3 detik.

Dari data yang didapat waktu yang dibutuhkan untuk memuat website Universitas XYZ adalah 35,47 detik, waktu yang sangat lama untuk memuat sebuah website. Dibutuhkan waktu memuat yang lebih cepat agar website tidak memiliki bounce rate yang tinggi dan optimasi site speed pada website Universitas XYZ.

\section{Implementasi On-Page SEO}

Untuk meningkatkan peringkat website Universitas XYZ di hasil pencarian Google, pada penelitian ini akan dilakukan implementasi on-page metode SEO. Optimasi ini mengoptimalkan halaman website agar dapat masuk peringkat teratas di SERP dan mudah dicari oleh pengunjung website. Optimasi yang dilakukan dimulai dari mengoptimalkan meta description, optimasi ALT tag pada gambar, internal link, dan juga site speed.

Optimasi pertama yang dilakukan adalah mengoptimasi meta description dan keyword. Agar website mudah untuk diindeks oleh mesin pencari, optimasi meta description dan keyword perlu dilakukan. Meta description memudahkan pengunjung website untuk mengetahui secara umum isi 
konten sebuah website dan tertarik untuk mengunjungi website tersebut. Dengan meta description yang menarik, traffic website tentunya dapat meningkat. Penginputan meta description dilakukan menggunakan Yoast SEO.

$$
\text { www. - Translate this page }
$$

Penerimaan Mahasiswa Baru -

Daftar Sekarang. Dapatkan Promo Terbaik! Subscribe dan dapatkan informasi terkini seputar Penerimaan Mahasiswa Baru 2021/2022 . Panduan Lengkap PMB 2021/2022 ...

\section{Gambar 8. Meta Description Setelah Dioptimasi}

Optimasi kedua adalah mengoptimasi gambar pada website Universitas XYZ. Optimasi gambar meliputi penerapan dari unsur dasar gambar serta penggunaan gambar pada skrip HTML atau PHP. Optimasi tersebut antara lain: 1) menggunakan tipe file atau format gambar yang dikenali oleh Google, antara lain jpg, gif, png; 2) dimensi gambar yang tidak melebihi 750px; 3) mengurangi ukuran gambar untuk mempercepat proses loading; 4) penamaan file gambar yang pendek tapi deskriptif; dan 5) menggunakan ALT tag pada gambar, untuk memberitahu mesin pencari informasi atau deskripsi dari gambar tersebut.

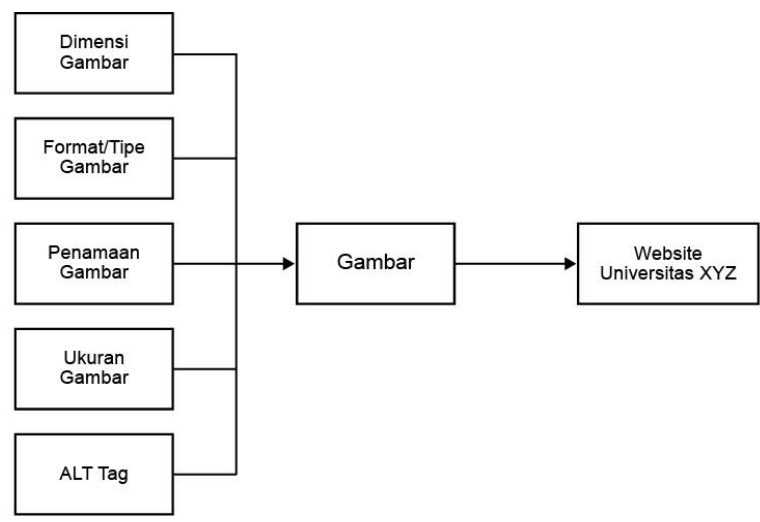

Gambar 9. Flow Diagram Optimasi Gambar

SEOptimer digunakan untuk mengoptimasi ALT tag dan untuk mengidentifikasi gambar mana saja yang tidak memiliki ALT tag pada website Universitas XYZ. Melalui data yang didapat diketahui bahwa gambar website Universitas XYZ belum dioptimasi sebelumnya. Hal ini terlihat dari jumlah 37 gambar yang belum memiliki ALT tag dari 38 gambar pada halaman beranda website Universitas XYZ. ALT tag diinput pada semua gambar yang belum dioptimasi berdasarkan daftar gambar yang muncul di SEOptimer.

Optimasi berikutnya adalah optimasi internal link, agar memudahkan mesin pencari dalam menjelajahi, mengindeks serta melihat struktur website secara keseluruhan. Tautan ditambahkan pada halaman-halaman website untuk menghubungkan halaman satu dengan yang lainnya, dan tombol/link kembali untuk kembali ke halaman sebelumnya. Sehingga setiap halaman dapat terhubung satu sama lain dan membentuk struktur web yang diindeks dengan baik oleh mesin pencari.

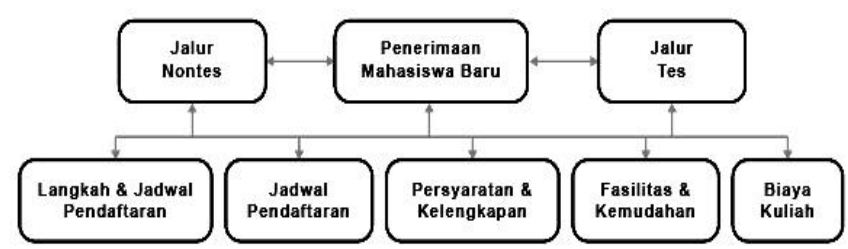

Gambar 10. Optimasi Internal Link pada Website Universitas XYZ

Optimasi terakhir adalah optimasi site speed untuk mempercepat waktu loading website dengan menggunakan Pingdom Tools. Optimasi dilakukan berdasarkan daftar optimasi yang diberikan oleh Pingdom Tools, seperti mengurangi ukuran gambar, menghindari redirect URL, dan mengompres komponen pada website.

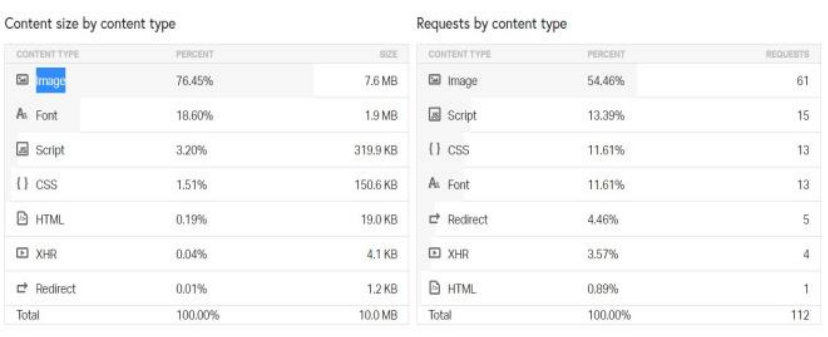

Gambar 11. Daftar Optimasi Site Speed dari Pingdom Tools

\section{Post-Test}

Pengujian post-test dilakukan untuk melihat kondisi website Universitas XYZ serta peringkatnya pada SERP setelah dilakukan implementasi on-page SEO. Serangkaian pengujian yang sama pada tahap pre-test dilakukan kembali untuk mengetahui perbedaan posisi peringkat pencarian serta kondisi website sebelum dan sesudah dilakukan optimasi SEO pada website Universitas XYZ.

Pengujian dimulai dengan menggunakan Google Analytics untuk mendapatkan data traffic website Universitas XYZ setelah implementasi on-page SEO dan didapatkan data sebagai berikut:

\section{TABEL V}

DATA TRAFFIC WEBSITE UNIVERSITAS XYZ SETELAH IMPLEMENTASI SEO

\begin{tabular}{|l|l|l|c|}
\hline \multicolumn{1}{|c|}{ Pageviews } & $\begin{array}{c}\text { Unique } \\
\text { Pageviews }\end{array}$ & $\begin{array}{c}\text { Bounce } \\
\text { Rate }\end{array}$ & \%Exit \\
\hline 311.101 & 229.708 & $41,75 \%$ & $40,28 \%$ \\
\hline
\end{tabular}

Dari Tabel V dapat diketahui jumlah kualitas pengunjung dengan cara:

- Nilai yang bukan bounce rate (\%) $100 \%-41,75 \%=58,25 \%$

- Jumlah yang membaca dan mem-browser website Universitas XYZ adalah:

(jumlah unique pageviews) $\mathrm{x}$ (bukan bounce rate)

$229.708 \times 58,25 \%=133.805$ pengunjung

Jadi, ada sebanyak 133.805 pengunjung yang benar-benar membaca website Universitas XYZ. Jika dibandingkan 
dengan data traffic website sebelum implementasi SEO pada Tabel II, terjadi peningkatan secara signifikan yaitu sebesar $207,4 \%$. Bounce rate juga berkurang sebesar $15,35 \%$. Angak ini menunjukkan peningkatan yang sangat besar terhadap traffic website Universitas XYZ setelah implementasi SEO.

Pengujian berikutnya adalah menggunakan PageRank kembali untuk mengetahui peringkat website Universitas XYZ di hasil pencarian Google setelah implementasi SEO. Setelah implementasi SEO, terjadi peningkatan peringkat dibandingkan dengan data Tabel III sebelum dilakukan implementasi SEO.

TABEL VI

Perbandingan Data PeringKat Website Universitas XYZ MENGGUNAKAN PAGERANK SETELAH DAN SEBELUM IMPLEMENTASI SEO

\begin{tabular}{|c|l|c|c|}
\hline No. & \multicolumn{1}{|c|}{ Indikator } & $\begin{array}{c}\text { Hasil } \\
\text { Pre-test }\end{array}$ & $\begin{array}{c}\text { Hasil } \\
\text { Post-test }\end{array}$ \\
\hline 1 & Global Rank & 78.012 & 80.665 \\
\hline 2 & Alexa Reach Rank & 72.753 & 77.841 \\
\hline
\end{tabular}

Pengujian kembali dilakukan menggunakan SEO Site Checkup untuk mengetahui penilaian SEO terhadap website tersebut. Dari pengujian yang dilakukan didapatkan hasil seperti pada Gambar 12.

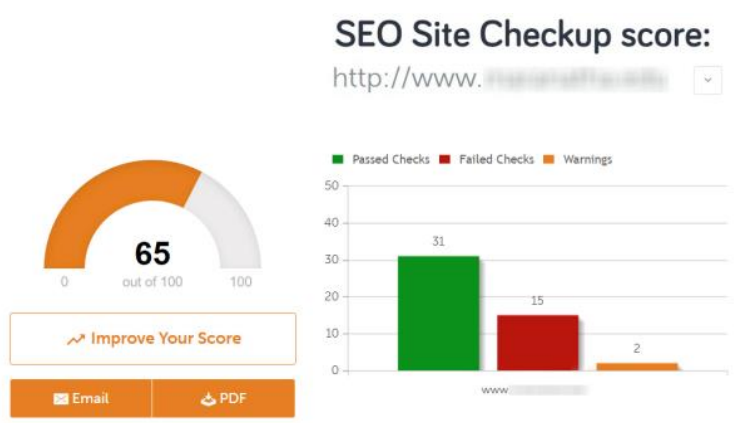

Gambar 12. SEO Site Checkup Score Sebelum Implementasi SEO

Nilai yang diperoleh adalah 65/100, hasil ini menunjukkan terdapat peningkatan yang cukup signifikan sebesar 23 dibandingkan pengujian website sebelum implementasi SEO dan sudah memiliki meta description dan image ALT tag, serta masalah umum SEO lainnya sudah dioptimasi. Data dari SEO Site Checkup menunjukkan bahwa website Universitas XYZ sudah dioptimasi.

TABEL VII

DAFTAR MASALAH UMUM YANG SUDAH DiOPTIMASI

\begin{tabular}{|c|l|c|c|}
\hline \multirow{2}{*}{ No. } & \multicolumn{2}{|c|}{ Masalah Umum } & \multicolumn{2}{c|}{ Status Optimasi } \\
\cline { 3 - 4 } & & Sudah & Belum \\
\hline 1 & Meta title & $\mathrm{V}$ & \\
\hline 2 & Meta description & $\mathrm{V}$ & \\
\hline 3 & Heading tags & $\mathrm{V}$ & \\
\hline 4 & Image ALT tag & $\mathrm{V}$ & \\
\hline 5 & Internal link & $\mathrm{V}$ & \\
\hline 6 & Site speed & $\mathrm{V}$ & \\
\hline
\end{tabular}

Pengujian kembali dilakukan pada gambar website dengan menggunakan SEOptimer untuk memastikan tidak ada gambar yang belum dioptimasi dan idak ditemukan lagi gambar yang belum dioptimasi. Hasil pencarian gambar sudah menampilkan gambar yang sesuai dengan kata kunci yang diinput di mesin pencari yang berarti gambar pada website Universitas XYZ sudah berhasil diindeks oleh webcrawler mesin pencari.

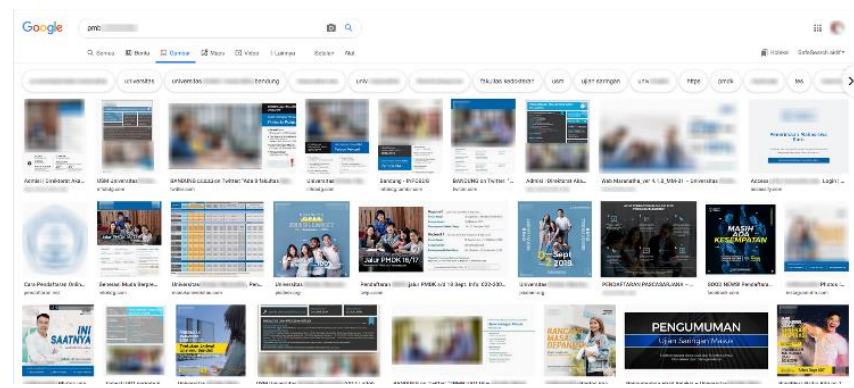

Gambar 13. Behavior Flow di Google Analytics Setelah Implementasi SEO

Berikutnya dilakukan pengujian internal link dengan menggunakan Google Analytics. Halaman website kini sudah lebih terstruktur, terlihat dari behavior flow sebanyak 12 interaction setelah optimasi internal link yang sebelumnya hanya sebanyak 7 interaction. Gambar 13 di bawah ini menunjukkan behavior flow dari pengunjung website Universitas XYZ setelah optimasi internal link.

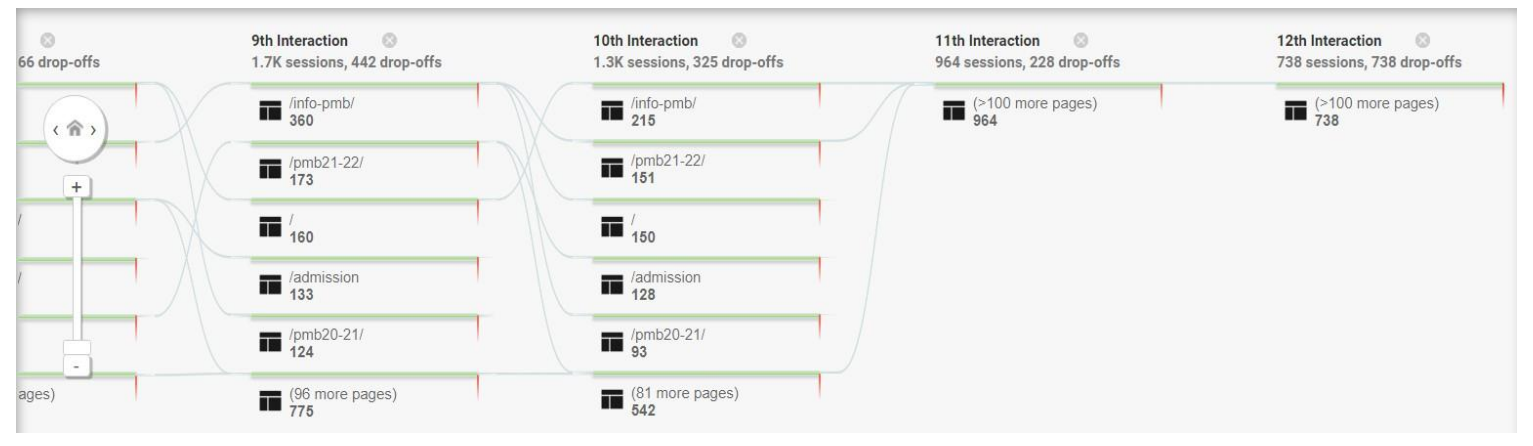

Gambar 14. Behavior Flow di Google Analytics Setelah Implementasi SEO 
Kemudian dilakukan kembali pengujian site speed dari website Universitas XYZ menggunakan Pingdom Tools dan didapatkan hasil pada Gambar 14. Setelah optimasi website dapat dimuat $44,4 \%$ lebih cepat dibandingkan dengan sebelum optimasi dan ukuran beranda website dapat direduksi sebesar 5,4 MB.

Your Results:

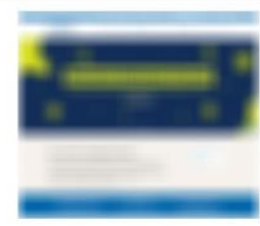

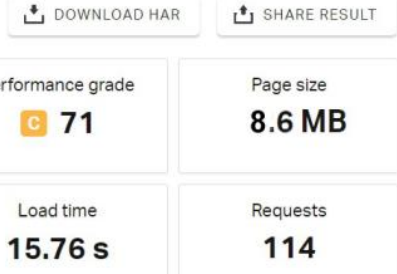

Gambar 15. Hasil Pengujian Site Speed Menggunakan Pingdom Tools Setelah Implementasi SEO

Pengujian post-test terakhir dilakukan terhadap sepuluh kata kunci yang didapatkan pada saat analisis kata kunci dengan menggunakan Whatsmyserp untuk mengetahui peringkat website Universitas XYZ setelah implementasi SEO. Tabel VI menunjukkan bahwa implementasi SEO terhadap website Universitas XYZ telah berhasil dilakukan dan meningkatkan peringkat sepuluh kata kunci tersebut pada hasil pencarian Google. Namun terdapat beberapa penurunan peringkat untuk beberapa kata kunci hal ini dikarenakan site speed website Universitas XYZ yang sangat lambat yang dipengaruhi oleh faktor masalah server.

TABEL VIII

TABEL PERINGKAT SERP WEBSITE UNIVERSITAS XYZ BERDASARKAN KATA KUNCI SETELAH IMPLEMENTASI SEO

\begin{tabular}{|l|c|c|c|c|}
\hline \multirow{2}{*}{$\begin{array}{c}\text { Rekomendasi Kata } \\
\text { Kunci }\end{array}$} & $\begin{array}{c}\text { Posisi } \\
\text { Saat } \\
\text { Ini }\end{array}$ & $\begin{array}{c}\text { Pari } \\
\text { Lalu }\end{array}$ & $\begin{array}{c}\text { 1 } \\
\text { Mingg } \\
\text { u Lalu }\end{array}$ & $\begin{array}{c}\text { Pulan } \\
\text { Bulan } \\
\text { Lalu }\end{array}$ \\
\cline { 2 - 5 } & 65 & - & - & - \\
\hline $\begin{array}{l}\text { jurusan kuliah } \\
\text { bandung }\end{array}$ & 28 & 29 & 34 & 38 \\
\hline masuk kampus & - & - & - & - \\
\hline
\end{tabular}

\begin{tabular}{|l|c|c|c|c|}
\hline \multirow{2}{*}{$\begin{array}{c}\text { Rekomendasi Kata } \\
\text { Kunci }\end{array}$} & $\begin{array}{c}\text { Posisi } \\
\text { Saat } \\
\text { Ini }\end{array}$ & $\begin{array}{c}\mathbf{1} \\
\text { Hari } \\
\text { Lalu }\end{array}$ & $\begin{array}{c}\text { Peringkat SERP } \\
\text { Mingg } \\
\text { u Lalu }\end{array}$ & $\begin{array}{c}\mathbf{1} \\
\text { Bulan } \\
\text { Lalu }\end{array}$ \\
\hline beasiswa kuliah & 18 & 22 & 19 & 35 \\
\hline $\begin{array}{l}\text { universitas swasta } \\
\text { terbaik }\end{array}$ & 33 & 30 & 25 & 47 \\
\hline fakultas kedokteran & 24 & 25 & 27 & 32 \\
\hline $\begin{array}{l}\text { penerimaan mahasiswa } \\
\text { baru }\end{array}$ & 34 & 38 & 32 & 46 \\
\hline $\begin{array}{l}\text { kampus terbaik di } \\
\text { bandung }\end{array}$ & 43 & 46 & 48 & - \\
\hline perguruan tinggi swasta & 41 & 34 & 53 & - \\
\hline $\begin{array}{l}\text { perguruan tinggi swasta } \\
\text { terbaik }\end{array}$ & 56 & 54 & 51 & - \\
\hline
\end{tabular}

Dari data Tabel VI tersebut, website Universitas XYZ sudah memiliki peringkat pada sepuluh kata kunci tersebut di hasil pencari Google sehingga pengunjung dapat lebih mudah untuk menemukan website Universitas XYZ di mesin pencari. Implementasi metode SEO yang telah dilakukan telah berhasil meningkatkan peringkat website Universitas XYZ di mesin pencari Google.

Setelah semua pengujian dilakukan, data hasil peringkat website Universitas XYZ dari sebelum dan sesudah implementasi SEO dihitung menggunakan paired sample $t$ test dengan rumus:

$$
t=\frac{\overline{x 1}-\overline{x 2}}{\sqrt{\frac{s_{1}^{2}}{n_{1}}+\frac{s_{2}^{2}}{n_{2}}-2 r\left(\frac{s_{1}}{\sqrt{n_{1}}}\right)\left(\frac{s_{2}}{\sqrt{n_{2}}}\right)}}
$$

Untuk memudahkan perhitungan perbandingan 2 sample yang didapat dari pre-test dan post-test, maka seluruh perhitungan paired sample t-test dilakukan dengan bantuan SPSS 21.0 sehingga tidak diperlukan melakukan perbandingan antara hasil penelitian dengan tabel statistik karena dari output komputer dapat diketahui besarnya nilai p diakhiri semua teknik statistik yang diuji, dan dihasilkan data pada Tabel IX di bawah ini.

TABEL IX

PAIRED SAMPLE T-TEST PERINGKAT Website UNIVERSITAS XYZ

\begin{tabular}{|c|c|c|c|c|c|c|c|c|c|}
\hline & \multicolumn{5}{|c|}{ Paired Difference } & \multirow{3}{*}{$\mathbf{t}$} & \multirow{3}{*}{$\mathbf{p}$} & \multirow{3}{*}{ df } & \multirow{3}{*}{ Sig. } \\
\hline & \multirow[t]{2}{*}{ Mean } & \multirow[t]{2}{*}{$\begin{array}{c}\text { Std. } \\
\text { Defiation }\end{array}$} & \multirow[t]{2}{*}{$\begin{array}{l}\text { Std. } \\
\text { Error } \\
\text { Mean }\end{array}$} & \multicolumn{2}{|c|}{$\begin{array}{c}\text { 95\% Confidence } \\
\text { Interval of } \\
\text { the Difference }\end{array}$} & & & & \\
\hline & & & & Lower & Upper & & & & \\
\hline $\begin{array}{l}\text { Sebelum } \\
\text { dan Sesudah } \\
\text { Implementasi } \\
\text { SEO }\end{array}$ & 38 & 172,181 & 8,367 & 32,351 & 17,025 & $-3,179$ & 0,019 & 9 & 0.008 \\
\hline
\end{tabular}


Didapatkan nilai t hitung $=-3,179$ dan nilai $-\mathrm{p}=0,019<$ 0,05 sehingga hipotesis $\mathrm{h}_{0}$ ditolak. Dari hasil tersebut maka disimpulkan jika implementasi metode on-page SEO pada website Universitas XYZ mampu meningkatkan peringkat website di hasil pencari Google dibandingkan dengan tanpa implementasi SEO.

\section{KESIMPULAN DAN SARAN}

Dari hasil implementasi SEO yang dilakukan dalam penelitian ini, maka dapat ditarik kesimpulan bahwa:

1. Implementasi metode SEO sangat berpengaruh terhadap peringkat website Universitas XYZ di mesin pencari Google. Hal ini dibuktikan dengan peningkatan peringkat website di hasil pencarian mesin pencari setelah implementasi SEO yang dilakukan.

2. Optimasi meta description membantu untuk menarik pengguna internet untuk mengunjungi website, terlihat dari bertambahnya pengunjung pada saat optimasi dilakukan.

3. Optimasi internal link pada sebuah website dapat memperbaiki struktur website dan mempermudah mesin pencari untuk mengindeks website, hal ini dibuktikan dari penambahan sebanyak 5 interaction pada behavior flow pengunjung website serta penurunan bounce rate sebesar $15,35 \%$.

4. Optimalisasi terhadap gambar dapat meningkatkan hasil pencarian gambar di mesin pencari Google, karena membantu indeks yang dilakukan web-crawler terhadap sebuah gambar yang ditunjukkan dengan kesesuaian antara hasil pencarian gambar dengan kata kunci yang dicari oleh pengguna. Selain itu penggunaan gambar dalam sebuah halaman website tidak hanya sebagai pelengkap atau pemanis halaman saja, tetapi dapat di gunakan dalam optimasi sebuah website untuk meningkatkan peringkat di SERP.

5. Penggunaan ALT tag sangat dominan dan efisien dalam proses pengindeksan yang dilakukan oleh mesin pencari Google terhadap sebuah gambar sehingga hasil pencarian gambar dapat lebih sesuai dengan yang dicari oleh pengguna.

6. Cepat tidaknya sebuah website untuk dimuat sangat berpengaruh pada peringkat website di SERP, terbukti dari penurunan peringkat SERP pada beberapa halaman di website Universitas XYZ yang ditunjukkan oleh Whatsmyserp, dan membatasi peningkatan peringkat pada website.

7. Dibutuhkan konsistensi dalam optimasi SEO pada sebuah website agar dapat mempertahankan peringkat hasil pencarian di mesin pencari. Tanpa konsistensi optimasi, maka implementasi SEO menjadi sia-sia, karena akan berdampak pada penurunan peringkat website itu sendiri.

Dengan adanya beberapa kekurangan yang dilakukan dalam penelitian ini, dapat disimpulkan beberapa saran yang bertujuan untuk meningkatkan penelitian selanjutnya, yaitu bahwa metode SEO perlu dilakukan secara rutin, karena konsistensi optimasi yang dilakukan akan sangat berpengaruh pada peringkat website di hasil pencarian. Hal ini dapat terlihat dari penurunan peringkat di hasil pencarian dan performa website yang terjadi setelah tidak adanya optimasi yang dilakukan setelah penelitian selesai dilakukan. Perlu adanya maintenance optimasi SEO secara rutin agar dapat meningkatkan serta mempertahankan peringkat di hasil pencarian mesin pencari.

\section{DAFTAR PUSTAKA}

[1] Azis Barbar \& Anis Ismail, "Search Engine Optimization (SEO) for Website," Association for Computing Machinery, pp. 51-55, 2019.

[2] Maria Agustina, "Search Engine Optimization", Andi Yogyakarta, 2009.

[3] Wang Bin \& Gao Bingyun, "A Study on Tactics for College Website at Search Engine Optimization," IEEE 3rd International Conference on Big Data Analysis, pp. 259-263, 2018.

[4] Li-Hsing Ho \& Jui-Chen Huang, "The Application of Search Engine Optimization for Internet Marketing: An Example of the Motel Websites," Institute of Electrical and Electronics Engineers, pp. 380383, 2010

[5] Paulus Yesaya, "Google SEO Mendongkrak Situs Anda ke Peringkat Puncak," Yogyakarta: Andi \& Elcom, 2011.

[6] Mr. K. Tarakeswar \& Ms. D. Kavitha, "Search Engines: A Study," Journal of Computer Applications (JCA), vol. 4, issue 1, pp. 29-30, 2011.

[7] Jalaludin Rakhmat, "Metode Penelitian Komunikasi," Bandung: PT Remaja Rosdakarya, 2009.

[8] Halilintar R. B. \& Ariyus D., "Implementasi SEO (Search Engine Optimization) Pada Website AGC (Auto Generated Content) Untuk Meningkatkan SERP (Search Engine Result Page) Studi Kasus: Website Gallery," Seminar Nasional Teknologi Informasi dan Multimedia, pp. 13-18, 2018

[9] Salma Gaou, Aissam Bekkari, Marouane El Mabrouk, dan Abdelhamid Zouhair, "Search Engine Optimization to Detect User's Intent," The 2nd International Conference, 2017.

[10] Dr. Birgit Weischedel \& Dr. Eelko K.R.E. Huizingh, "Website Optimization with Web Metrics: A Case Study," International Conference on Electrical Contacts, pp. 463-470, 2006.

[11] Mo Yunfeng, "A Study on Tactics for Corporate Website Development Aiming at Search Engine Optimization," IEEE, vol. 3, 2010.

[12] Chaitanya Vyas, " Evaluating State Tourism Websites Using Search Engine Optimization Tools," Tourism Management, pp. 64-70, 2019.

[13] Li-Hsing Ho \& Jui-Chen Huang, "The Application of Search Engine Optimization for Internet Marketing: An Example of the Motel Websites," IEEE, 2010. 